\title{
Effects of two kinds of fishery drugs on the expressions of GAD and GABA-T mRNA in crucian carp (Carassius auratus gibelio)
}

\author{
Fan Zhang • Kun Hu • Jianzhen Huang • Zhi Tan • \\ Jiming Ruan (1)
}

Received: 16 December 2019/Accepted: 7 July 2020 / Published online: 15 July 2020

(C) The Author(s) 2020

\begin{abstract}
The objective of this study was to investigate the effects of difloxacin (DIF) and avermectin (AVM) on glutamate decarboxylase (GAD) and GABAtransaminase (GABA-T) in different tissues of crucian carp (Carassius auratus gibelio). After the treatments of DIF and AVM, the mRNA expressions of GAD and GABA-T in different tissues were detected by quantitative real-time PCR (qPCR). The results showed that the mRNA expressions of $\mathrm{GAD}_{65}, \mathrm{GAD}_{67}$, and GABA-T in the telencephalon (Tel), mesencephalon (Mes), cerebella (Cer), and medulla oblongata (Med) were downregulated significantly with the safe dose (SD, $20 \mathrm{mg} / \mathrm{kg}$ ) of DIF $(P<0.05$ or $P<0.01)$. While the expressions of $\mathrm{GAD}_{65}$ and $\mathrm{GAD}_{67}$ in the kidney at $12 \mathrm{~h}$ had strikingly upregulated to $13.81 \pm 1.06^{* *}$ and $150.67 \pm 12.85^{* *}$ times. Treated with the lethal dose of $50 \%\left(\mathrm{LD}_{50}\right.$, $2840 \mathrm{mg} / \mathrm{kg} \mathrm{b}$. W.) of DIF, the mRNA expressions of $\mathrm{GAD}_{65}, \mathrm{GAD}_{67}$, and GABA-T in all tissues were increased significantly $(P<0.01)$. The results of AVM group showed that the mRNA expressions of $\mathrm{GAD}_{65}$, $\mathrm{GAD}_{67}$, and GABA-T both in the central and peripheral
\end{abstract}

Fan Zhang and Kun $\mathrm{Hu}$ are co-first authors.

F. Zhang $\cdot$ J. Huang $\cdot$ Z. Tan $\cdot$ J. Ruan $(\bowtie)$

Department of Aquaculture, College of Animal Science and Technology, Jiangxi Agricultural University, Nanchang 330045, China

e-mail: rjm903@163.com

K. Hu

National Center for Aquatic Pathogen Collection, College of Fisheries and Life Science, Shanghai Ocean University, Shanghai 201306, China tissues were all remarkably downregulated at the safe concentration (SC, $0.0039 \mathrm{mg} / \mathrm{L}$ ) and the lethal concentration of $50 \%\left(\mathrm{LC}_{50}, 0.039 \mathrm{mg} / \mathrm{L}\right)$, except for the mRNA inhibitions of $\mathrm{GAD}_{65}, \mathrm{GAD}_{67}$, and GABA-T in the muscle at $2 \mathrm{~h}$ which sharply downregulated to $0.20 \pm 0.02^{\Delta \Delta} \times 10^{-2}, 0.57 \pm 0.06^{\Delta \Delta} \times 10^{-1}$ and $0.44 \pm$ $0.02^{\Delta \Delta} \times 10^{-1}$, respectively $(P<0.01)$.

Keywords Gamma-aminobutyric acid - Difloxacin . Avermectin - Glutamate decarboxylase - GABAtransaminase

\section{Introduction}

GABA, an important inhibitory neurotransmitter in many organisms, along with glutamate (Glu), is involved in the neuromodulation of most synaptic activity. GABA arises via decarboxylation of L-glutamate by glutamate decarboxylase (GAD) (Chung et al. 1992) and is metabolized subsequently via GABA-transferase (GABA-T) to succinic semialdehyde, which is then oxidized to succinate (Wood et al. 1978). This process would directly affect the accumulations of GABA in organisms. The changes of Glu and GABA in nerve endings would result in rearrangements of the nervous system that increases neural activity (Nasreen et al. 2012). The production and metabolism of GABA can be predicted by observing changes in the expression of enzymes present in nerve endings.

However, many factors affect how well GABA works, which include heavy metal (Struzyńska and Sulkowski 2004), antibiotics (Matsuo et al. 1998), 
Table 1 Information of primers of the paper

\begin{tabular}{lllr}
\hline Genes & Primer sequence $\left(5^{\prime}-3^{\prime}\right)$ & GenBank ID & Size (bp) \\
\hline$\beta$-Actin & $\begin{array}{l}\text { Forward TACGTTGCCATCCAGGCTGTG } \\
\text { Reverse CATGGGGCAGGGCGTAACC }\end{array}$ & M24113.1 & 124 \\
GAD $_{65}$ & $\begin{array}{l}\text { Forward TTCTCTGTCGCTGCTCTGAT } \\
\text { Reverse CTCTCGGCTGTAGACCCAT }\end{array}$ & AF149832.1 & 246 \\
GAD $_{67}$ & $\begin{array}{l}\text { Forward GTTTTCTGATATCAAGCGTCTCAC } \\
\text { Reverse TGGCAGGTTGTCGTAAATTAG }\end{array}$ & AF149833.1 & 209 \\
GABA-T & $\begin{array}{l}\text { Forward GCTGCCTGGCCACAACACA } \\
\text { Reverse TCCCTCACAAACTCCTCCAGA }\end{array}$ & DQ287923.1 & 115 \\
& & & 56.4 \\
\hline
\end{tabular}

insecticide (Sánchez-Borzone et al. 2017), and other biological toxins (Kudryavtsev et al. 2015). The imbalances of excitatory or inhibitory neurotransmitters caused by drugs can lead to nerve abnormalities, causing organisms to exhibit symptoms of nerve poisoning.

Fluoroquinolones (FQs) were widely used in aquaculture due to its good bactericidal effect in China. Its family includes difloxacin (DIF), ofloxacin, pefloxacin, enoxacin, norfloxacin, etc. However, the side effects of FQs have been widely reported in recent years, such as its muscular toxicity (Demetrious 2018), renal toxicity (Owens and Ambrose 2005), and neurotoxicity (Xiao et al. 2018). Many reports suggested FQs could have caused severe neurotoxic reactions, which lead to hallucinations, depression, and other neurological diseases (Barrett and Login 2009; Grill and Maganti 2011; Guiol et al. 1993). It had been reported that norfloxacin (Xi et al. 2019) and DIF (Ruan et al. 2014a) caused non-target biological neurotoxicity. Albino male mice treated with ciprofloxacin were found the levels of Glu and GABA significantly reduced (Arafa et al. 2015). While as a broad-spectrum insecticide, avermectin (AVM) was also widely used for parasites killing in aquaculture. The problems of non-target biological poisoning caused by AVM were becoming more and more serious, including in birds (de Faria et al. 2018a, b), fish (Novelli et al. 2016), batrachians (Vasconcelos et al. 2016), and mammals (Nasr et al. 2016). Experiments on Danio rerio (Weichert et al. 2017), mice (Da et al. 2018), and pigeon ( $\mathrm{Li}$ et al. 2013) had been found that AVM could cause neurotoxicity. On specific physiological and biochemical indicators, AVM exposure enhanced the contents of GABA, glycine, Glu, and aspartic acid in the cerebrum, cerebellum, and optic lobe of American king pigeons significantly (Chen et al. 2014). Crucian carp (Carassius auratus gibelio) is one of the tremendous economic value fish which widely cultivated in China. Therefore, this paper intends to study the possible variations of GABA's synthetase and metabolic enzyme in crucian carp after treated with DIF and AVM.

\section{Materials and methods}

Experimental animals and fishery drugs

Crucian carp were bought from a farm in Nantong City, Jiangsu Province, east of China as experimental fish, which body weights were $50.04 \pm 3.12 \mathrm{~g}$, and fed for 2 weeks before the beginning of the experiments. Plenty of oxygen was pumped into the water during the whole experiment. Temperature and $\mathrm{pH}$ values were maintained in the right range of crucian carp. All the fish were fed twice per day.

The SD and the lethal dose of 50\% at $96 \mathrm{~h}(96 \mathrm{~h}$ $\mathrm{LD}_{50}$ ) of DIF were $20 \mathrm{mg} / \mathrm{kg} \mathrm{b}$. W. and $2840 \mathrm{mg} / \mathrm{kg} \mathrm{b}$. $\mathrm{W}$. which referred from the previous study (Ruan et al.
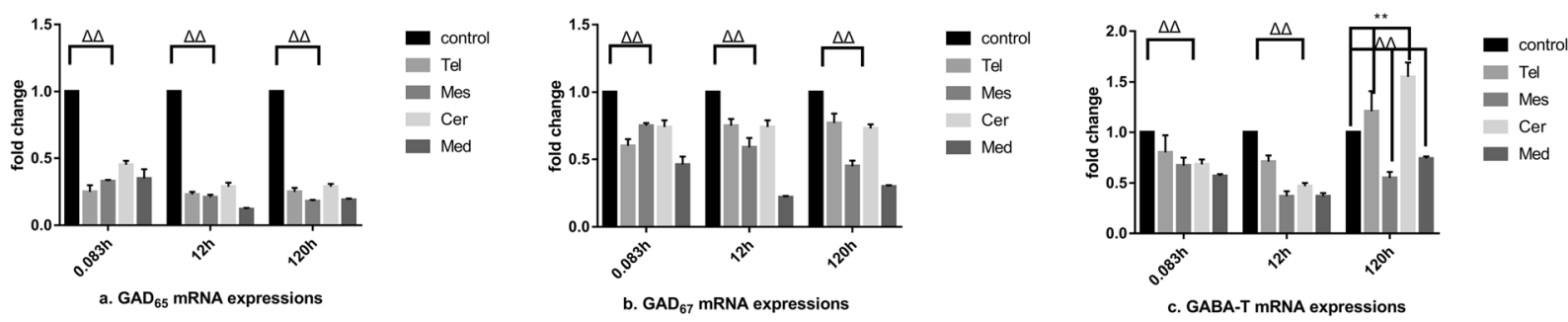

Fig. 1 Effects in brain GAD and GABA-T mRNA expressions at the SD of DIF 

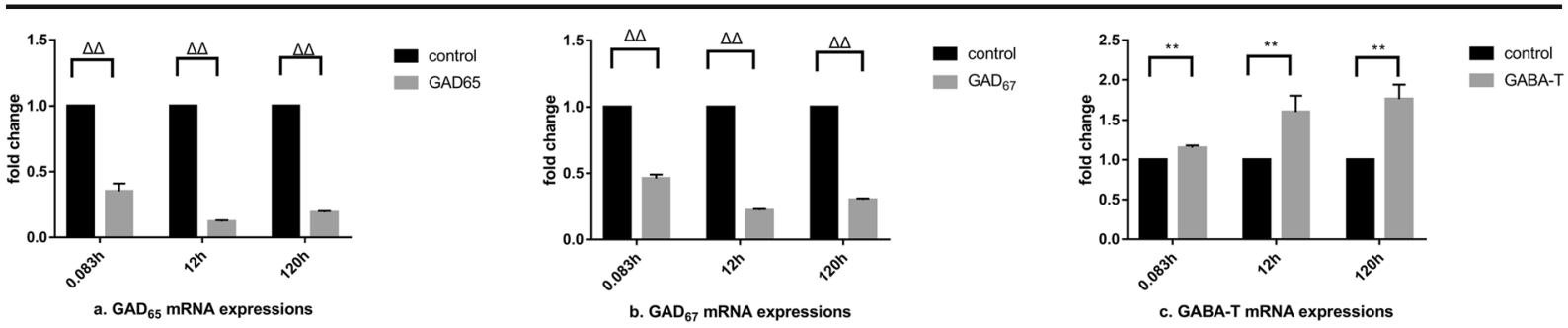

Fig. 2 Effects of GAD and GABA-T mRNA expressions in the liver at the SD of DIF

2014a). According to the body weights of the experimental fish, DIF was singly orally administered into the foregut of the experimental fish.

The SC and $96 \mathrm{~h} \mathrm{LC}_{50}$ of AVM were $0.0039 \mathrm{mg} / \mathrm{L}$ and $0.039 \mathrm{mg} / \mathrm{L}$ by the method of single bath administration (Ruan et al. 2013).

The sample collections

The experimental fish were randomly divided into three groups at the corresponding dose/concentration, 60 fish per group. Samples of Tel, Mes, Cer, Med, liver, kidney, and muscle were collected and stored at $-80{ }^{\circ} \mathrm{C}$ for the mRNA extractions. All fish were handled following the "Regulation on Animal Experimentation."

Total RNA extraction, reverse transcription, RT-PCR analysis, and qPCR analysis

The procedures of total RNA extraction, RT-PCR, and qPCR analysis were referred from the previous article (Ruan et al. 2014b). The primers pairs were shown in the Table 1 .

\section{Data processing}

The comparative threshold method $\left(2^{-\Delta \Delta C T}\right)$ was employed to calculate the relative expression of the genes. The data were expressed as mean \pm standard deviation (SD) and SPSS 17.0 (Chicago, IL, USA) was used for one-way ANOVA, where $P<0.05$ and $P<0.01$, respectively, indicated significant and extremely significant difference.

\section{Results and analysis}

Analysis of genes expressions in the brain at the SD of DIF

From Fig. $1 \mathrm{a}$ and $\mathrm{b}$, it could be found that $\mathrm{GAD}_{65}$ and $\mathrm{GAD}_{67}$ expressions were significantly suppressed $(P<0.01)$ in the crucian carp's brain by SD of DIF $(20 \mathrm{mg} / \mathrm{kg} \mathrm{b}$. W.) after treatment at $0.083,2$, and $120 \mathrm{~h}$. The volumes and the time-points which $\mathrm{GAD}_{65}$ expressions remarkably inhibited were $0.25 \pm 0.05^{\Delta \Delta}$ at $0.083 \mathrm{~h}$ in Tel, $0.12 \pm 0.01^{\Delta \Delta}$ at $12 \mathrm{~h}$ in Med, and 0.18 $\pm 0.01^{\Delta \Delta}$ at $120 \mathrm{~h}$ in Mes, respectively (Fig. 1a). GAD 67 levels were strongly suppressed in Med, and the changes in which were $0.46 \pm 0.06^{\Delta \Delta}$ times at $0.083 \mathrm{~h}, 0.22 \pm$ $0.01^{\Delta \Delta}$ times at $12 \mathrm{~h}$, and $0.30 \pm 0.01^{\Delta \Delta}$ times at $120 \mathrm{~h}$ times (Fig. 1b). The same as $\mathrm{GAD}_{67}$, GABA-T gene in Med and the changes of which were $0.57 \pm 0.02^{\Delta \Delta}$ times at $0.083 \mathrm{~h}, 0.37 \pm 0.03^{\Delta \Delta}$ times at $12 \mathrm{~h}$, and $0.55 \pm 0.06^{\Delta \Delta}$ times at $120 \mathrm{~h}$ (Fig. 1c). However, GABA-T levels were significantly upregulated in Tel and $\mathrm{Cer}$ at $120 \mathrm{~h}$, and their volumes were $1.21 \pm 0.20 * *$ and $1.55 \pm 0.14 * *(P<0.01)$.

Note: $0.083 \mathrm{~h}, 12 \mathrm{~h}$, and $120 \mathrm{~h}$ were the three-time points of DIF at the SD (20 mg/kg b. W.) (Ruan et al.
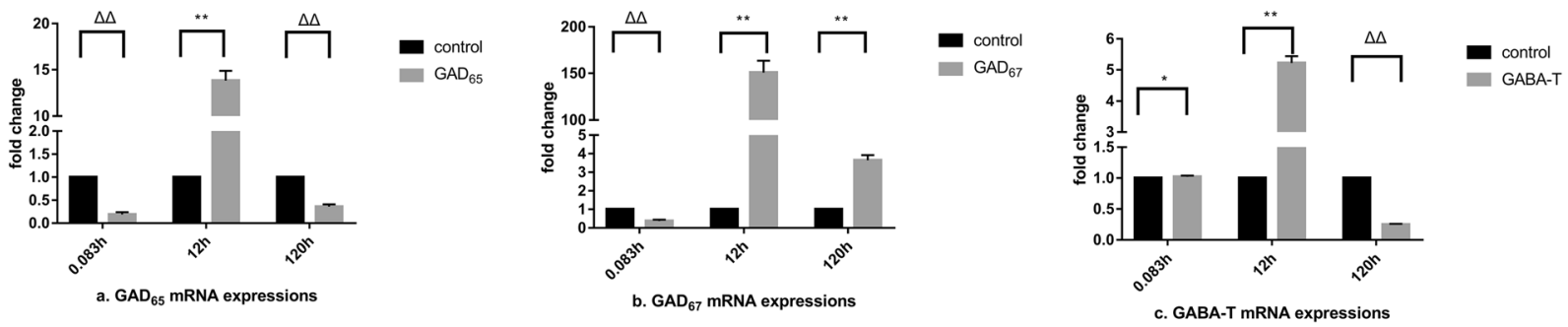

Fig. 3 Effects of GAD and GABA-T mRNA expressions in the kidney at the SD of DIF 
2014a). " $\Delta$ " and " $\Delta \Delta$, mean significant $(P<0.05)$ or extremely significant $(P<0.01)$ downregulation, while “*” and "**" mean significant $(P<0.05)$ or extremely significant $(P<0.01)$ upregulation. The same as followed.

Analysis of mRNA expressions in peripheral tissues at the SD of DIF

GAD expressions in the peripheral tissues were extremely significant inhibited by DIF $(P<0.01)$. As shown in Fig. $2 \mathrm{a}$ and $\mathrm{b}$ and, $\mathrm{GAD}_{65}$ and $\mathrm{GAD}_{67}$ genes were suppressed to minimums for $0.12 \pm 0.01^{\Delta \Delta}$ and $0.22 \pm 0.01^{\Delta \Delta}$ at $12 \mathrm{~h}$, while GABA-T genes were significantly upregulated in the liver. The maximum changes of GABA-T were $1.76 \pm 0.18^{* *}$ times at $120 \mathrm{~h}$ in the liver (Fig. 2c). GAD and GABA-T levels appeared consistent trends as first decreasing, then increasing, and decreasing in the kidney. Among them, $\mathrm{GAD}_{65}$ levels were $0.19 \pm 0.05^{\Delta \Delta}$ at $0.083 \mathrm{~h}, 13.81 \pm$ $1.06^{* *}$ at $12 \mathrm{~h}$, and $0.36 \pm 0.05^{\Delta \Delta}$ at $120 \mathrm{~h}$ (Fig. $3 \mathrm{a}$ ), while $\mathrm{GAD}_{67}$ levels were $0.37 \pm 0.08^{\Delta \Delta}$ at $0.083 \mathrm{~h}$, $150.67 \pm 12.85^{* *}$ at $12 \mathrm{~h}$, and $3.64 \pm 0.28^{*}$ at $120 \mathrm{~h}$ (Fig. 3b). Moreover, GABA-T gene were $1.02 \pm 0.02 *$ at $0.083 \mathrm{~h}, 5.22 \pm 0.22 * *$ at $12 \mathrm{~h}$, and $0.25 \pm 0.01^{\Delta \Delta}$ at $120 \mathrm{~h}$ (Fig. 3c). GAD 65 level was greatly inhibited in the muscle, and its minimum value was $0.04 \pm 0.008^{\Delta \Delta}$ at 0.083 h (Fig. 4a), while $\mathrm{GAD}_{67}$ level was extremely significant increased with a maximum change of $2.89 \pm$ $0.58^{* *}$ times at $12 \mathrm{~h}$ (Fig. $4 \mathrm{~b}$ ). GABA-T levels were $0.68 \pm 0.05^{\Delta \Delta}$ at $0.083 \mathrm{~h}, 1.37 \pm 0.14^{* *}$ at $12 \mathrm{~h}$, and $0.93 \pm 0.08^{\Delta \Delta}$ at $120 \mathrm{~h}$ (Fig. 4c), which also showed a same trend as "decreasing — increasing — decreasing."

Analysis of mRNA expressions at $\mathrm{LD}_{50}$ of DIF

The $\mathrm{GAD}_{65}, \mathrm{GAD}_{67}$, and GABA-T levels were extremely increased both in the brain and peripheral tissues of the crucian carp at $\mathrm{LD}_{50}$ of DIF $(P<0.01$, Tables 2 and 3 ). The volumes of extremely stimulated
Table $2 \mathrm{GAD}_{65}, \mathrm{GAD}_{67}$, and GABA-T mRNA expressions at $\mathrm{LD}_{50}$ of DIF

\begin{tabular}{llll}
\hline Tissues & GAD $_{65}$ & GAD $_{67}$ & GABA-T \\
\hline Tel & $1.02 \pm 0.14$ & $2.41 \pm 0.09^{* *}$ & $1.04 \pm 0.16^{* *}$ \\
Mer & $1.08 \pm 0.8^{* *}$ & $1.38 \pm 0.23^{* *}$ & $1.03 \pm 0.11^{* *}$ \\
Cer & $2.25 \pm 0.16^{* *}$ & $1.79 \pm 0.06^{* *}$ & $1.12 \pm 0.18^{* *}$ \\
Med & $1.41 \pm 0.07^{* *}$ & $1.57 \pm 0.11^{* *}$ & $1.97 \pm 0.23^{* *}$ \\
Liver & $1.41 \pm 0.07^{* *}$ & $1.57 \pm 0.21^{* *}$ & $1.04 \pm 0.16^{* *}$ \\
Kidney & $3.81 \pm 0.19^{* *}$ & $8.46 \pm 1.43^{* *}$ & $1.03 \pm 0.11^{* *}$ \\
Muscle & $0.32 \pm 0.03^{\Delta \Delta}$ & $14.19 \pm 1.25^{* *}$ & $1.12 \pm 0.18^{* *}$ \\
\hline
\end{tabular}

$\mathrm{GAD}_{65}, \mathrm{GAD}_{67}$, and GABA-T levels were $2.25 \pm$ $0.16^{* *}$ in Cer, $2.41 \pm 0.09 * *$ in Tel, and $1.97 \pm 0.23 * *$ in Med (Table 2). As in the kidney, $\mathrm{GAD}_{65}$ and $\mathrm{GAD}_{67}$ levels were significantly increased by $3.81 \pm 0.19 * *$ and $8.46 \pm 1.43^{* *}$. A phenomenon in the muscle was that $\mathrm{GAD}_{65}$ level was suppressed by $0.32 \pm 0.03^{\Delta \Delta}$ times at $0.083 \mathrm{~h}$, while $\mathrm{GAD}_{67}$ and GABA-T levels were raised to $14.19 \pm 1.25 * *$ times and $1.12 \pm 0.18 * *$ times (Table 2).

Analysis of mRNA expressions in the brain at the SC of AVM

Treated by AVM, the levels of $\mathrm{GAD}_{65}, \mathrm{GAD}_{67}$, and GABA-T were extremely inhibited in the brain $(P<0.01$, Fig. 5). The volumes and the time-points which $\mathrm{GAD}_{65}$ expressions remarkably inhibited were $0.16 \pm 0.01^{\Delta \Delta}$ at $0.083 \mathrm{~h}$ in Mer, $0.17 \pm 0.01^{\Delta \Delta}$ at $2 \mathrm{~h}$ in Med, and $0.20 \pm 0.02^{\Delta \Delta}$ at $120 \mathrm{~h}$ in Mes, respectively (Fig. 5a). There were significantly downregulated $\mathrm{GAD}_{67}$ gene expressions in Med, which of the gene levels were $0.19 \pm 0.02^{\Delta \Delta}$ at $0.083 \mathrm{~h}, 0.14 \pm 0.02^{\Delta \Delta}$ at $2 \mathrm{~h}$, and $0.16 \pm 0.03^{\Delta \Delta}$ at $120 \mathrm{~h}$ (Fig. $5 \mathrm{~b}$ ). In contrast, the GABA-T level was less inhibited, with which was minimum by $0.53 \pm 0.06$ times at $0.083 \mathrm{~h}$ in Cer (Fig. $5 \mathrm{c}$ ).

Note: $0.083 \mathrm{~h}, 2 \mathrm{~h}$, and $120 \mathrm{~h}$ were the time points of AVM at the SC (0.0039 mg/L) (Ruan et al. 2013).
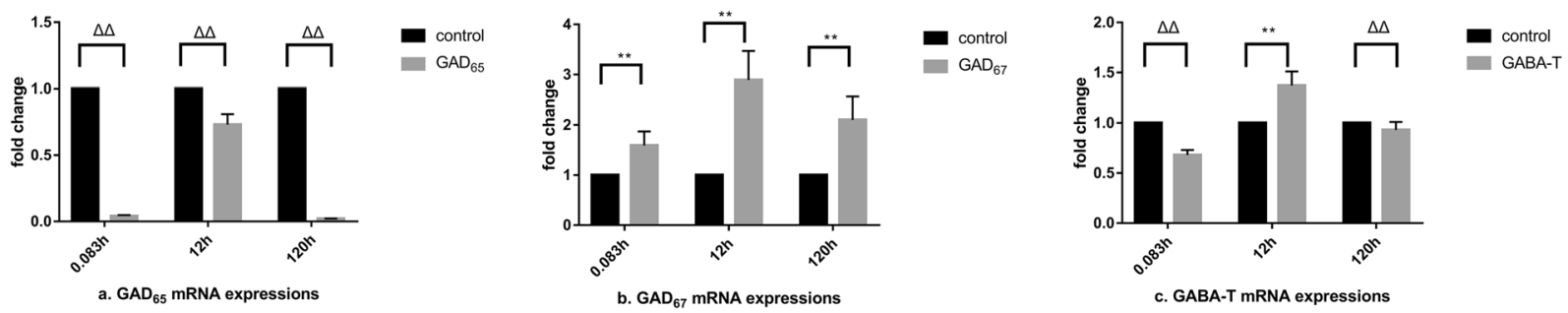

Fig. 4 Effects of GAD and GABA-T mRNA expressions in the muscle at the SD of DIF 
Table $3 \mathrm{GAD}_{65}, \mathrm{GAD}_{67}$ and GABA-T mRNA expressions at $\mathrm{LC}_{50}$ of AVM

\begin{tabular}{lllr}
\hline Tissues & GAD $_{65}$ & GAD $_{67}$ & GABA-T \\
\hline Tel & $0.17 \pm 0.03^{\Delta \Delta}$ & $0.32 \pm 0.05^{\Delta \Delta}$ & $0.83 \pm 0.02^{\Delta \Delta}$ \\
Mer & $0.12 \pm 0.01^{\Delta \Delta}$ & $0.23 \pm 0.02^{\Delta \Delta}$ & $0.66 \pm 0.05^{\Delta \Delta}$ \\
Cer & $0.41 \pm 0.02^{\Delta \Delta}$ & $0.61 \pm 0.09^{\Delta \Delta}$ & $0.68 \pm 0.05^{\Delta \Delta}$ \\
Med & $0.23 \pm 0.03^{\Delta \Delta}$ & $0.19 \pm 0.01^{\Delta \Delta}$ & $0.64 \pm 0.07^{\Delta \Delta}$ \\
Liver & $0.27 \pm 0.03^{\Delta \Delta}$ & $0.23 \pm 0.02^{\Delta \Delta}$ & $0.53 \pm 0.06^{\Delta \Delta}$ \\
Kidney & $0.36 \pm 0.06^{\Delta \Delta}$ & $0.35 \pm 0.04^{\Delta \Delta}$ & $0.91 \pm 0.09^{\Delta \Delta}$ \\
Muscle $\left(\times 10^{-1}\right)$ & $0.029 \pm 0.002^{\Delta \Delta}$ & $0.62 \pm 0.02^{\Delta \Delta}$ & $0.53 \pm 0.05^{\Delta \Delta}$ \\
\hline
\end{tabular}

Analysis of mRNA expressions in peripheral tissues at the SC of AVM

According to Fig. 6, the GAD and GABA-T levels in the liver were both strongly inhibited at the SC of AVM $\left(P<0.01\right.$, Fig. 6). $\mathrm{GAD}_{65}$ and $\mathrm{GAD}_{67}$ levels were remarkably suppressed to $0.09 \pm 0.01^{\Delta \Delta}$ at $0.083 \mathrm{~h}$ (Fig. 6a) and $0.05 \pm 0.01^{\Delta \Delta}$ at $2 \mathrm{~h}$ (Fig. 6b). GABA-T genes were inhibited significantly, with minimum of which was $0.23 \pm 0.02^{\Delta \Delta}$ at $2 \mathrm{~h}$ in the liver (Fig. 6c), and expressions of GABA-T showed as a "high-lowhigh" trend. The GAD and GABA-T levels were also significantly downregulated in the kidney. In general, the volumes and the time-points which $\mathrm{GAD}_{65}, \mathrm{GAD}_{67}$, and GABA-T levels remarkably inhibited were $0.52 \pm$ $0.05^{\Delta \Delta}$ at $0.083 \mathrm{~h}$ (Fig. 7a), $0.06 \pm 0.01^{\Delta \Delta}$ at $0.083 \mathrm{~h}$ (Fig. 7b), and $0.26 \pm 0.02^{\Delta \Delta}$ at $2 \mathrm{~h}$ (Fig. 7c), respectively. Similarly, GAD and GABA-T levels in the muscle were also inhibited strongly. The largest variation range of $\mathrm{GAD}_{65}, \mathrm{GAD}_{67}$, and GABA-T were $0.20 \pm 0.02^{\Delta \Delta^{\Delta}} \times$ $10^{-2}$ (Fig. 8a), $0.57 \pm 0.06^{\Delta \Delta} \times 10^{-1}$ (Fig. 8b), and 0.44 $\pm 0.02^{\Delta \Delta} \times 10^{-1}$ times greater (Fig. 8c) at $2 \mathrm{~h}$, respectively.

Analysis of mRNA expressions at the $\mathrm{LC}_{50}$ of $\mathrm{AVM}$

$\mathrm{GAD}_{65}, \mathrm{GAD}_{67}$, and GABA-T levels both in the brain and peripheral tissues were significantly downregulated
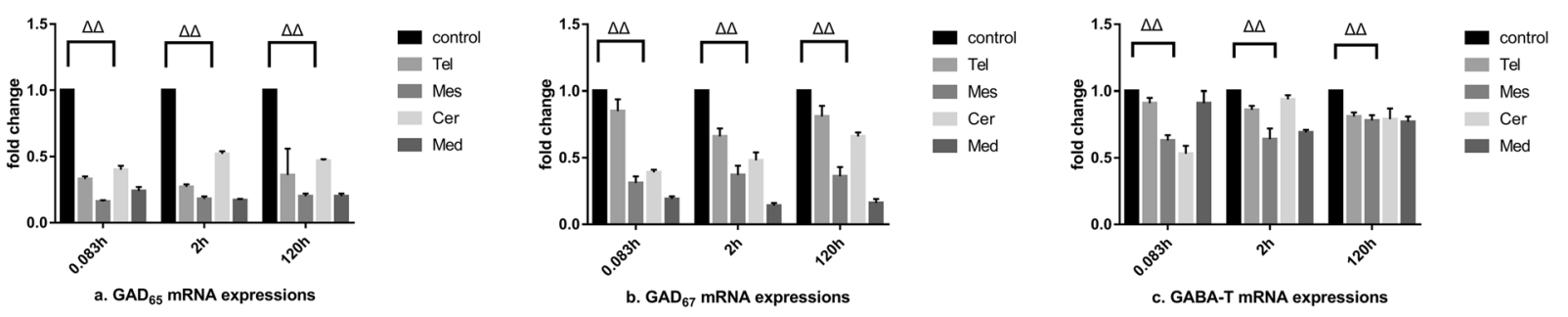

$(P<0.01)$ at $96 \mathrm{~h} \mathrm{LC}_{50}(0.039 \mathrm{mg} / \mathrm{L}) . \mathrm{GAD}_{65}$ level was inhibited significantly to $0.12 \pm 0.01^{\Delta \Delta}$ in Mer. Furthermore, $\mathrm{GAD}_{67}$ and GABA-T levels with minimum values were $0.19 \pm 0.01^{\Delta \Delta}$ and $0.64 \pm 0.07^{\Delta \Delta}$ in Med (Table 3). Compared to the liver, $\mathrm{GAD}_{65}, \mathrm{GAD}_{67}$, and GABA-T levels in the kidney were less inhibited. And the mRNA expressions of $\mathrm{GAD}_{65}, \mathrm{GAD}_{67}$, and GABA$\mathrm{T}$ were $0.36 \pm 0.06^{\Delta \Delta}, 0.35 \pm 0.04^{\Delta \Delta}$, and $0.91 \pm$ $0.09^{\Delta \Delta}$, respectively. GAD and GABA-T levels in the muscle were inhibited strongly, where the relative expressions of $\mathrm{GAD}_{65}, \mathrm{GAD}_{67}$, and GABA-T were $0.0029 \pm 0.0002^{\Delta \Delta}, 0.062 \pm 0.002^{\Delta \Delta}$, and $0.053 \pm$ $0.005^{\Delta \Delta}$, respectively (Table 3 ).

\section{Discussions}

Effects of DIF on the mRNA expressions of GAD and GABA-T in crucian carp

It is generally believed that FQs antagonizes inhibitory neurotransmitter GABA, thereby increasing nerve excitability, leading to convulsions, epilepsy, and other adverse reactions (Motomura et al. 1991; Matsuo et al. 1998). GABA mediates the release of inhibitory synapses of neurons, which can reduce the hyperexcitability of neurons. Previous study found that crucian carp suffered from impatience and restlessness, body type

Fig. 5 Effects of GAD and GABA-T mRNA expressions in the brain at the SC of AVM 

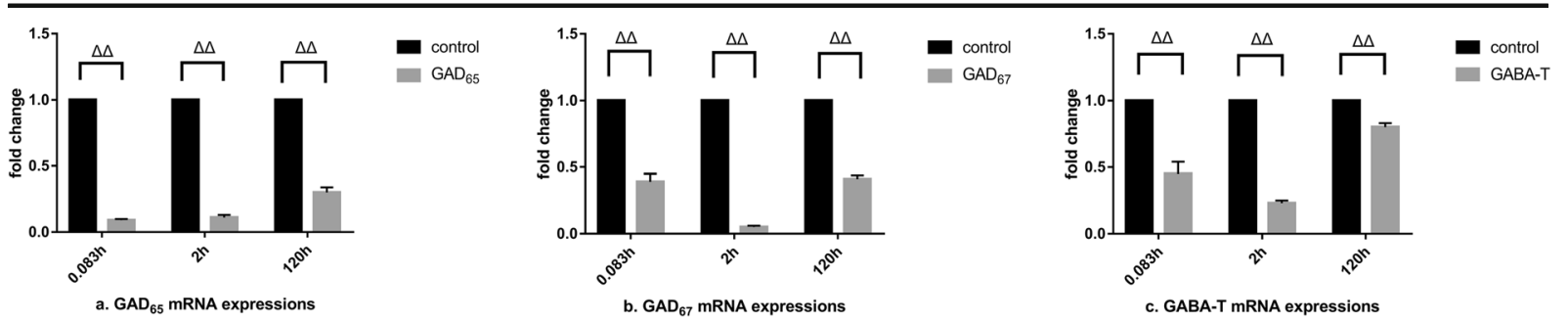

Fig. 6 Effects of GAD and GABA-T mRNA expressions in the liver at the SC of AVM

tremors when treated with DIF (Ruan et al. 2014a). Meanwhile, it was also found in this paper that $\mathrm{GAD}_{65}, \mathrm{GAD}_{67}$, and GABA-T levels were significantly downregulated at 0.083 and $12 \mathrm{~h}$ in the brain after administrated with DIF at its SD $(20 \mathrm{mg} / \mathrm{kg} \mathrm{b}$. W.), while $\mathrm{GAD}_{65}, \mathrm{GAD}_{67}$, and GABA-T levels were significantly upregulated at $\mathrm{LD}_{50}(2840 \mathrm{mg} / \mathrm{kg} \mathrm{b}$. W. $)$ of DIF ( $P<0.01$, Fig. 1 and Table 2$)$. However, GABA-T levels were significantly upregulated at $120 \mathrm{~h}$ in Tel and Cer after treated with DIF at its SD, which seemed to suggest that DIF could stimulate the overexpression of GABA-T to consume the GABA flux in the nerve center as an antagonistic inhibitor of GABA and enhance the convulsion effect of crucian carp. Moreover, the decreased GABA levels were also reported in the albino rat brain after intraperitoneal injection of FQS (Arafa et al. 2015). Similarly, GABA was continuously inhibited, resulting in epilepsy of old people after treated with FQS (Isaacson et al. 1993). These pieces of evidence suggested that the systemic neurotoxicity of crucian carp may be related to the upregulation of mRNA levels of GAD and GABA-T in various tissues treated with the lethal dose of DIF.

After the treatments at SD or $\mathrm{LD}_{50}$ of DIF, GABA-T level was significantly increased $(P<0.01)$ in the liver (Fig. 2 and Table 2). While GAD levels were of different expressions at the two doses, which may be lead to the accumulation of GABA in the liver for the reason of DIF. In addition, GAD and GABA-T levels showed time-concentration effect after administration with DIF at its $\mathrm{SD}$ or $\mathrm{LD}_{50}$ in the kidney (Fig. 4). This may suggested that low dose of DIF would inhibit GABA pathway, while high dose (or high residual) has opposite performance, the same as the effect of DIF on the central nervous system. This phenomenon may be a protective mechanism of stress resistance in crucian carp.

Effects of AVM on the mRNA expressions of GAD and GABA-T in crucian carp

GABA levels in organisms were determined by the dynamic balance between synthesis and catabolism and regulated by the level of GAD, precursor availability, and possibly GABA degradation (de Graaf et al. 2006). It has been reported that the neurotoxicity of AVM to organisms was due to its ability to trigger the opening of $\mathrm{Cl}^{-}$channels (Lasota and Dybas 1991). This process was irreversible and only occurred in invertebrates (Cornejo et al. 2014). In addition, the neurotoxicity of AVM was also reflected in the destruction of a large number of nerve cells (Shu et al. 2010). After been exposed to AVM at the SC $(0.0039 \mathrm{mg} / \mathrm{L})$ and $\mathrm{LC}_{50}$ $(0.039 \mathrm{mg} / \mathrm{L})$, the mRNA expressions of GAD and GABA-T both in the brain and peripheral tissues of crucian carp were inhibited significantly in this paper ( $P<0.01$, Figs. 4, 5, 6, 7, 8 and Table 3). This result indicated that the central nervous system was influenced by AVM in crucian carp. It was found that the mRNA levels of $\mathrm{GAD}_{65}, \mathrm{GAD}_{67}$, and GABA-T in the goldfish's brain were downregulated after treatment with GABA receptor agonists (Martyniuk et al. 2007). Similar results were found in this paper.
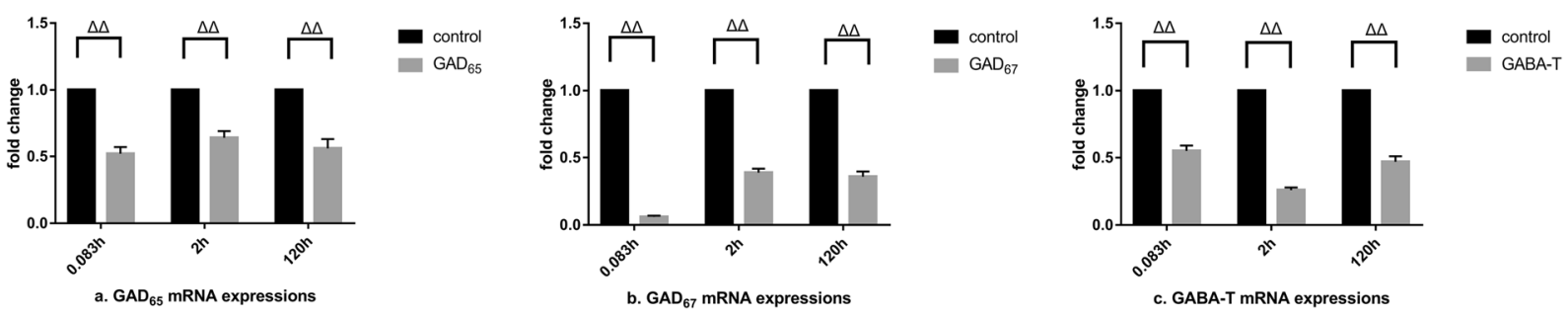

Fig. 7 Effects of GAD and GABA-T mRNA expressions in the kidney at the SC of AVM 

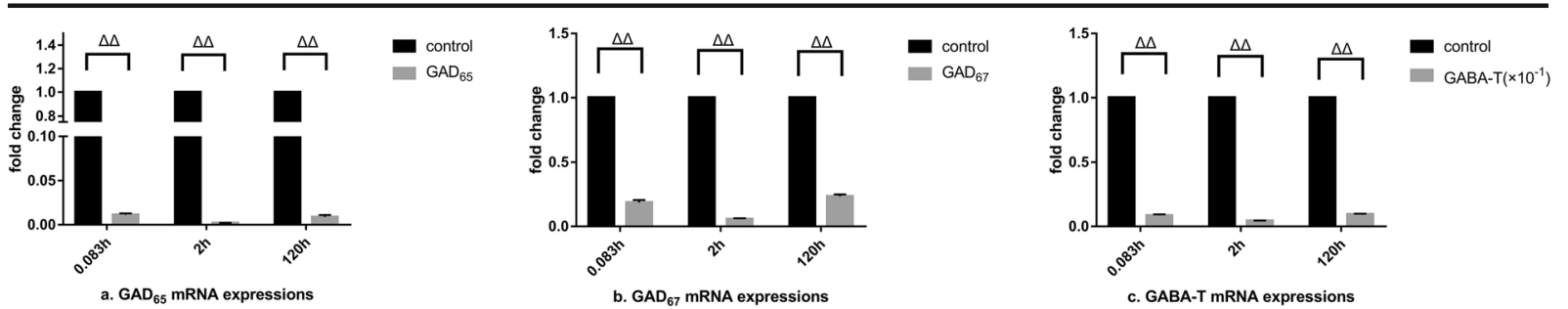

Fig. 8 Effects of GAD and GABA-T mRNA expressions in the muscle at the SC of AVM

Interestingly, GABA-T was inhibited to a much lower degree than that of GAD's in the brain at $\mathrm{LC}_{50}$ of AVM. Based on previous research, the GAD level was much higher than that of GABA-T in the brain, which seemed to indicate that AVM would causes different expression of GAD and GABA-T (Ruan et al. 2014b). But on the contrary, GAD and GABA-T levels were extremely inhibited in the muscle after treated with AVM at the SC or at the $\mathrm{LC}_{50}$ (Fig. 8 and Table 3), which suggested that neuromuscular synthesis and metabolic rate of GABA were stagnant. This may lead to an imbalance in muscular nerve regulation, such as pathological convulsion of muscle. Similar findings were also found that the status of crucian carp was in physical imbalance and has a slower respiration rate after AVM treatments (Wang and $\mathrm{Lu}$ 2010). After been exposed to AVM, it was discovered that Japanese quails has a decrease of response to its natural enemies (de Faria et al. 2018b). Other paper found that AVM would cause twitching and keep exciting in bees; this may relate to the fact that AVM inhibits the expressions of GAD and GABA-T in the cerebellum (Zhao et al. 2014). Besides, deltamethrin and $\beta$-cypermethrin could downregulate GABA-T level in the cerebral cortex of rats, which resulting in an increase in GABA level ( $\mathrm{Ji}$ et al. 2003; Han et al. 2014). All the evidences mentioned above suggested that AVM would break through the blood-brain barrier, which lead to the increase of GABA through affecting the mRNA expressions of $\mathrm{GAD}_{65}, \mathrm{GAD}_{67}$, and GABA-T in crucian carp's nervous system.

\section{Conclusion}

The expressions of $\mathrm{GAD}_{65}, \mathrm{GAD}_{67}$, and GABA-T were all significantly downregulated at the SD of DIF except for the upregulated expression of GABA-T in the kidney and muscle tissues at $120 \mathrm{~h}$, while the expressions of the three genes were significantly upregulated at the $\mathrm{LD}_{50}$ of DIF. In addition, the expressions of $\mathrm{GAD}_{65}, \mathrm{GAD}_{67}$, and GABA$\mathrm{T}$ in various tissues of crucian carp were significantly downregulated both at the $\mathrm{SC}$ and $\mathrm{LC}_{50}$ of $\mathrm{AVM}$.

Funding information This work was supported by the National Natural Science Foundation of China (No. 31860735) and the Science and Technology Support Project of Jiangxi Province (No. 20151BBF60056).

Open Access This article is licensed under a Creative Commons Attribution 4.0 International License, which permits use, sharing, adaptation, distribution and reproduction in any medium or format, as long as you give appropriate credit to the original author(s) and the source, provide a link to the Creative Commons licence, and indicate if changes were made. The images or other third party material in this article are included in the article's Creative Commons licence, unless indicated otherwise in a credit line to the material. If material is not included in the article's Creative Commons licence and your intended use is not permitted by statutory regulation or exceeds the permitted use, you will need to obtain permission directly from the copyright holder. To view a copy of this licence, visit http://creativecommons.org/licenses/by/4.0/.

\section{References}

Arafa N, Rawi MS, Mubarak SM, Abdullah S (2015) Exploration of the neurotoxicity of ciprofloxcin or gatifloxacin single dose in rat cortex and hippocampus. Afr J Pharm Pharmacol 9:65-73

Barrett MJ, Login IS (2009) Gemifloxacin-associated neurotoxicity presenting as encephalopathy. Ann Pharmacother 43:782-784

Chen LJ, Sun BH, Cao Y, Yao HD, Qu JP, Liu C, Xu SW, Li S (2014) The effects of avermectin on amino acid neurotransmitters and their receptors in the pigeon brain. Pestic Biochem Physiol 110:13-19

Chung I, Bown AW, Shelp BJ (1992) The production and efflux of 4-aminobutyrate in isolated mesophyll cells. Plant Physiol 99:659-664

Cornejo I, Andrini O, Niemeyer MI, Marabolí V, González-Nilo FD, Teulon J, Sepúlveda FV, Cid LP (2014) Identification and functional expression of a glutamate- and avermectingated chloride channel from Caligus rogercresseyi, a 
southern hemisphere sea louse affecting farmed fish. PLoS Pathog 10:e1004402

Da SW, Guimarães A, Montalvão MF, Mendes BO, Rodrigues A, Malafaia G (2018) The chronic exposure to abamectin causes spatial memory deficit and depressive behavior in mice. Chemosphere 194:523-533

de Faria D, Montalvão MF, de Souza JM, de Oliveira MB, Malafaia G, Rodrigues A (2018a) Analysis of various effects of abamectin on erythrocyte morphology in Japanese quails (Coturnix japonica). Environ Sci Pollut Res Int 25:24502456

de Faria D, Montalvão MF, Chagas TQ, Araújo A, Souza JM, Mendes BO, Rodrigues A, Malafaia G (2018b) Behavioral changes in Japanese quails exposed to predicted environmentally relevant abamectin concentrations. Sci Total Environ 636:1553-1564

de Graaf RA, Patel AB, Rothman DL, Behar KL (2006) Acute regulation of steady-state GABA levels following GABAtransaminase inhibition in rat cerebral cortex. Neurochem Int 48:508-514

Demetrious JS (2018) Spontaneous cervical artery dissection: a fluoroquinolone induced connective tissue disorder? Chiropr Man Therap 26:22

Grill MF, Maganti RK (2011) Neurotoxic effects associated with antibiotic use: management considerations. Br J Clin Pharmacol 72:381-393

Guiol C, Ledoussal C, Surgé JM (1993) Pharmacological properties of a new fluoroquinolone on the central nervous system in rodents. Arzneimittelforschung 43:56-60

Han Y, Cao D, Li X, Zhang R, Yu F, Ren Y, An L (2014) Attenuation of $\gamma$-aminobutyric acid (GABA) transaminase activity contributes to GABA increase in the cerebral cortex of mice exposed to $\beta$-cypermethrin. Hum Exp Toxicol 33:317-324

Isaacson SH, Carr J, Rowan AJ (1993) Ciprofloxacin-induced complex partial status epilepticus manifesting as an acute confusional state. Neurology 43:1619-1621

Ji ZY, Shi N, Wang SQ, Dong J, Chen MS (2003) Effects of pyrethroids on the activity of gamma-aminobutyric acid transferase in rat brain. Zhonghua Lao Dong Wei Sheng Zhi Ye Bing Za Zhi 21:197-199

Kudryavtsev DS, Shelukhina IV, Son LV, Ojomoko LO, Kryukova EV, Lyukmanova EN, Zhmak MN, Dolgikh DA, Ivanov IA, Kasheverov IE, Starkov VG, Ramerstorfer J, Sieghart W, Tsetlin VI, Utkin YN (2015) Neurotoxins from snake venoms and $\alpha$ conotoxin ImI inhibit functionally active ionotropic $\gamma$ aminobutyric acid (GABA) receptors. J Biol Chem 290:2274722758

Lasota JA, Dybas RA (1991) Avermectins, a novel class of compounds: implications for use in arthropod pest control. Annu Rev Entomol 36:91-117

Li M, You TZ, Zhu WJ, Qu JP, Liu C, Zhao B, Xu SW, Li S (2013) Antioxidant response and histopathological changes in brain tissue of pigeon exposed to avermectin. Ecotoxicology 22:1241-1254

Martyniuk CJ, Chang JP, Trudeau VL (2007) The effects of GABA agonists on glutamic acid decarboxylase, GABA-transaminase, activin, salmon gonadotrophin-releasing hormone and tyrosine hydroxylase mRNA in the goldfish (Carassius auratus) neuroendocrine brain. J Neuroendocrinol 19:390-396

Matsuo H, Ryu M, Nagata A, Uchida T, Kawakami JI, Yamamoto K, Iga T, Sawada Y (1998) Neurotoxicodynamics of the interaction between ciprofloxacin and foscarnet in mice. Antimicrob Agents Chemother 42:691-694

Motomura M, Kataoka Y, Takeo G, Shibayama K, Ohishi K, Nakamura T, Niwa M, Tsujihata M, Nagataki S (1991) Hippocampus and frontal cortex are the potential mediatory sites for convulsions induced by new quinolones and nonsteroidal anti-inflammatory drugs. Int J Clin Pharmacol Ther Toxicol 29:223-227

Nasr HM, El-Demerdash FM, El-Nagar WA (2016) Neuro and renal toxicity induced by chlorpyrifos and abamectin in rats: toxicity of insecticide mixture. Environ Sci Pollut Res Int 23:1852-1859

Nasreen Z, Jameel T, Hasan A, Parveen N, Sadasivudu B (2012) Glutamate decarboxylase and GABA aminotransferase levels in different regions of rat brain on the onset of Leptazol induced convulsions. Neurochem Res 37:202-204

Novelli A, Vieira BH, Braun AS, Mendes LB, Daam MA, Espíndola EL (2016) Impact of runoff water from an experimental agricultural field applied with Vertimec ${ }^{\circledR}$ 18EC (abamectin) on the survival, growth and gill morphology of zebrafish juveniles. Chemosphere 144:1408-1414

Owens RJ, Ambrose PG (2005) Antimicrobial safety: focus on fluoroquinolones. Clin Infect Dis 41(Suppl 2):S144-S157

Ruan J, Hu K, Yang X (2013) Permeability of avermectin to bloodbrain barrier and tissue residue in allogynogenetic crucian carp. Journal of Fishery Sciences of China 20:1032-1038

Ruan J, Hu K, Zhang H, Wang Y, Zhou A, Zhao Y, Yang X (2014a) Distribution and quantitative detection of GABAA receptor in Carassius auratus gibelio. Fish Physiol Biochem 40:1301-1311

Ruan J, Hu K, Yang X, Zhang H, Wang Y, Zhou A, Zhao Y (2014b) Permeability and elimination of difloxacin to bloodbrain barrier in allogynogenetic crucian carp. Acta Hydrobiologica Sinica 38:272-278

Sánchez-Borzone ME, Marin LD, García DA (2017) Effects of insecticidal ketones present in mint plants on $\mathrm{GABA}(\mathrm{A})$ receptor from mammalian neurons. Pharmacogn Mag 13:114-117

Shu L, Yali C, Min W, Shi-wen X, Jun-jie W (2010) Effect of avermectin on nerve cell apoptosis and nitric oxide level in pigeons. Chinese Journal of Animal and Veterinary Sciences 41:347-352

Struzyńska L, Sulkowski G (2004) Relationships between glutamine, glutamate, and GABA in nerve endings under $\mathrm{Pb}$ toxicity conditions. J Inorg Biochem 98:951-958

Vasconcelos AM, Daam MA, Dos SL, Sanches AL, Araújo CV, Espíndola EL (2016) Acute and chronic sensitivity, avoidance behavior and sensitive life stages of bullfrog tadpoles exposed to the biopesticide abamectin. Ecotoxicology 25:500-509

Wang X, Lu H (2010) Acute toxicity and histopathology of abamectin in Carassius auratus gibelio. Journal of Dalian Ocean University 25:66-70

Weichert FG, Floeter C, Meza AA, Kammann U (2017) Assessing the ecotoxicity of potentially neurotoxic substances - evaluation of a behavioural parameter in the embryogenesis of Danio rerio. Chemosphere 186:43-50 
Wood JD, Kurylo E, Newstead JD (1978) Aminooxyacetic acid induced changes in gamma-aminobutyrate metabolism at the subcellular level. Can J Biochem 56:667-672

Xi J, Liu J, He S, Shen W, Wei C, Li K, Zhang Y, Yue J, Yang Z (2019) Effects of norfloxacin exposure on neurodevelopment of zebrafish (Danio rerio) embryos. Neurotoxicology 72:85-94

Xiao C, Han Y, Liu Y, Zhang J, Hu C (2018) Relationship between fluoroquinolone structure and neurotoxicity revealed by zebrafish neurobehavior. Chem Res Toxicol 31: 238-250
Zhao YL, W. Y. G. J (2014) Acute toxicity and risk assessment of avermectin and its mixture on honeybees in Hainan. Chinese Journal of Environmental Entomology, 36, 744-748+704

Publisher's note Springer Nature remains neutral with regard to jurisdictional claims in published maps and institutional affiliations. 